\section{Commentary: The antifragility of the Melody valve}

\author{
Christoph Haller, MD, and Osami Honjo, MD, PhD
}

Atrioventricular valve replacement is considered a last resort in children with severe valvar dysfunction not amenable to repair, thereby asking for the impossible: a valve that is small enough to fit the patient but large enough to allow unobstructed inflow in a period of rapid somatic growth. Since the first description of the surgical implantation of a modified Melody stent-mounted valved bovine jugular vein graft (Medtronic, Minneapolis, Minn) in the mitral position in children, ${ }^{1}$ a large body of evidence has arisen proving its legitimacy as a valve replacement option in small children. Recent results have reported superiority compared with pericardial or porcine valves ${ }^{2}$ and advantages compared with mechanical valves smaller than $19 \mathrm{~mm}$ despite a greater need for reintervention. ${ }^{3,4}$ Despite the success of stented bovine jugular vein grafts for left atrioventricular valve replacement, it must not be forgotten that this valve prothesis is used off-label in this position. Modifications are necessary to allow surgical anchoring of the valve, and techniques limiting protrusion into the atrium and preventing left ventricular outflow tract obstruction have been reported. ${ }^{5}$ Therefore, it is essential to learn from experience and adjust technical aspects of the surgical procedure or even refine the valve itself to improve clinical outcomes.

A rare complication after replacement of a surgically implanted stented bovine jugular vein graft is reported in this issue of the Journal by Castellanos and colleagues. ${ }^{6}$ An 11-month-old child with a previously repaired partial atrioventricular septal defect underwent left atrioventricular valve replacement with a Melody valve, followed by

\footnotetext{
From the Department of Cardiovascular Surgery, The Labatt Family Heart Centre, The Hospital for Sick Children, University of Toronto, Toronto, Ontario, Canada. Disclosures: The authors reported no conflicts of interest.

The Journal policy requires editors and reviewers to disclose conflicts of interest and to decline handling or reviewing manuscripts for which they may have a conflict of interest. The editors and reviewers of this article have no conflicts of interest.

Received for publication Oct 20, 2020; revisions received Oct 20, 2020; accepted for publication Oct 20, 2020; available ahead of print Oct 23, 2020.

Address for reprints: Christoph Haller, MD, Division of Cardiovascular Surgery, The Hospital for Sick Children, 555 University Ave, Toronto, Ontario, Canada M5G 1X8 (E-mail: christoph.haller@sickkids.ca).

JTCVS Techniques 2020;4:251-2

2666-2507

Copyright (C) 2020 The Authors. Published by Elsevier Inc. on behalf of The American Association for Thoracic Surgery. This is an open access article under the CC BY-NCND license (http://creativecommons.org/licenses/by-nc-nd/4.0/).

https://doi.org/10.1016/j.xjtc.2020.10.020
}

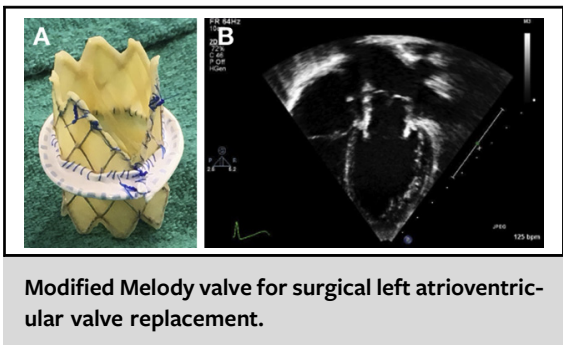

\author{
CENTRAL MESSAGE \\ Challenges and complications \\ associated with Melody valve \\ atrioventricular valve replace- \\ ments have only pushed this \\ technique further up to its \\ remarkably valuable position as a \\ prosthetic valve option in small \\ children.
}

2 balloon dilations postimplantation. The patient ultimately underwent re-replacement of the left atrioventricular valve with a 19-mm mechanical valve for severe regurgitation of the stented valve. Early postoperatively, a small left ventricular pseudoaneurysm was detected. The authors intervened successfully more than 1 year later once progression of the aneurysm was demonstrated.

Left ventricular pseudoaneurysms are a known complication of mitral valve replacement associated with high mortality. ${ }^{7}$ Specific pediatric data are scarce and limited to case reports and small series; however, there are certain characteristics of the Melody valve when used in the left atrioventricular position that may increase the risk for complications such as this. The orientation of the long cylinder of the valve is crucial to avoid obstruction of the left ventricular outflow tract. ${ }^{8}$ Thus, the distal aspect of the valve is fixed to the posterior aspect of the endocardium, shifting it away from the outflow tract axis. Consequently, the struts of the stent are pushing directly against the posterior free wall, putting it at risk of mechanical injury. This technique also makes dissection of the valve during valve re-replacement challenging, because a plane between the endocardial ventricular surface and the valve must be created. Previous reports have shown that although the valve leaflets can be relatively spared, the external conduit is encased in pannus, making removal of the valve particularly challenging. ${ }^{9,10}$ The location of the left ventricular pseudoaneurysm described by Castellanos and colleagues seems to be this very area of 

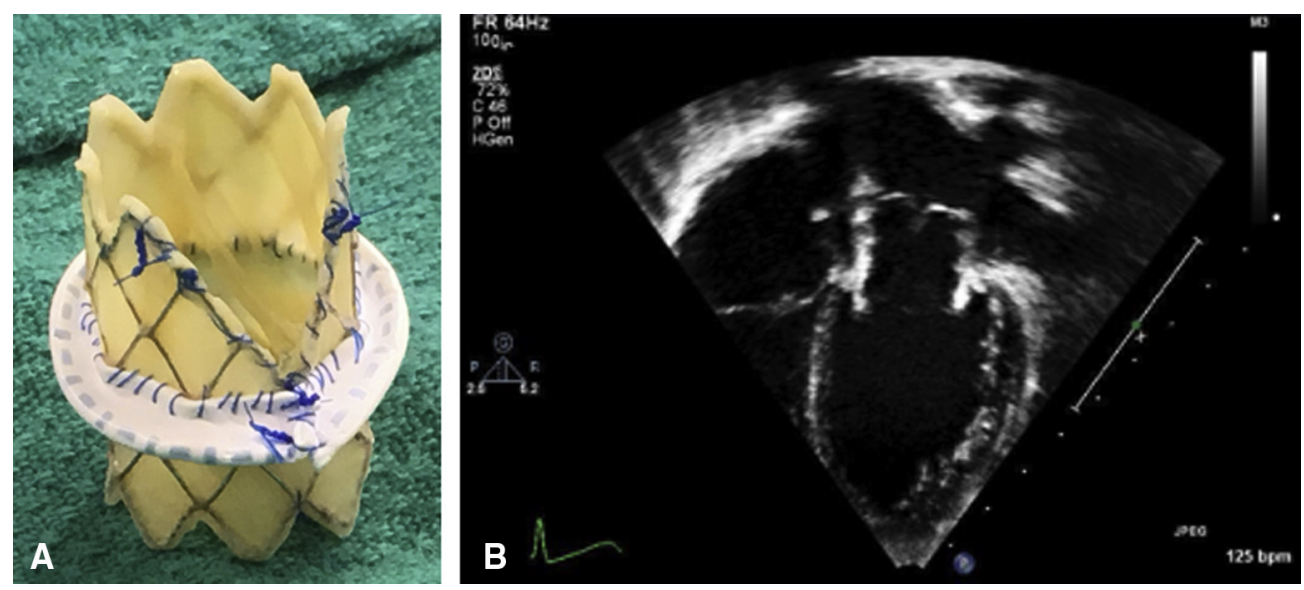

FIGURE 1. A, Melody valve with polytetrafluoroethylene cuff and wedge cutout to prevent left ventricular outflow tract obstruction. B, Echocardiography after implantation of the Melody valve showing its position in relation to the left atrioventricular valve annulus and posterolateral free wall.

abutment of endocardium and conduit. Oversizing of the balloon on expansion of the valve, as well as repeat dilations may further contribute to myocardial thinning, areas of localized ischemia, and structural weakening of the posterior ventricular wall, ultimately allowing it to rupture after removal of the stented valve. We are currently using a 4-mm polytetrafluoroethylene tube graft (WL Gore \& Associates, Flagstaff, Ariz) as a sewing cuff for the valve. This material has proven to be nonadherent and to facilitate relatively easy removal. ${ }^{9}$ The position of the cuff can also ensure limited protrusion of the valve into the left ventricle, further reducing the risk of posterior wall compromise (Figure 1).

The case report by Castellanos and colleagues highlights a new complication associated with the Melody valve in the left atrioventricular position. It stresses the importance of careful removal of the valve and thorough inspection of the ventricular wall and other surrounding structures, as well as a close follow-up of patients after valve replacement. Considering the high risk associated with ventricular pseudoaneurysms, early intervention is advisable in most patients, although extensive pericardial adhesions may help contain free rupture. Does this report diminish the reputation of the stented bovine jugular vein graft as an atrioventricular valve replacement in children? Certainly not. It reminds us that we are meeting the lack of specific pediatric medical devices in cardiac surgery with surgical ingenuity and that we thrive with these challenges through constant reassessment, adjustment, and advancement.

\section{References}

1. Abdullah I, Ramirez FB, McElhinney DB, Lock JE, del Nido PJ, Emani S. Modification of a stented bovine jugular vein conduit (melody valve) for surgical mitral valve replacement. Ann Thorac Surg. 2012;94:e97-8.

2. Choi PS, Sleeper LA, Lu M, Upchurch P, Baird C, Emani SM. Revisiting prosthesis choice in mitral valve replacement in children: durable alternatives to traditional bioprostheses. J Thorac Cardiovasc Surg. 2021;161:213-25.

3. Ijsselhof RJ, Slieker MG, Gauvreau K, Muter A, Marx JR, Hazekamp MG, et al. Mechanical mitral valve replacement: a multicenter study of outcomes with use of 15- to 17-mm prostheses. Ann Thorac Surg. 2020;110:2062-9.

4. Pluchinotta FR, Piekarski BL, Milani V, Kretschmar O, Burch PT, Hakami L, et al. Surgical atrioventricular valve replacement with Melody valve in infants and children: a multicenter study. Circ Cardiovasc Interv. 2018;11:1-11.

5. Emani SM. Melody valve for mitral valve replacement. Oper Tech Thorac Cardiovasc Surg. 2014;19:454-63.

6. Castellanos DA, Jaquiss RDB, Thankavel PP. Left ventricular pseudoaneurysm after replacement of a melody valve in the left atrioventricular valve position. J Thorac Cardiovasc Surg Tech. 2020;4:248-50.

7. Frances C, Romero A, Grady D. Left ventricular pseudoaneurysm. J Am Coll Cardiol. 1998;32:557-61.

8. Choi PS, Nam HH, Lasso A, Herz C, Drouin S, Harrild DM, et al. Three-dimensional modeling of surgically implanted stent-based valves in the mitral position in children. Ann Thorac Surg. 2020;110:670-5.

9. Luo S, Honjo O. A bridge to heart transplant: systemic atrioventricular valve replacement with a Melody valve in an infant with a single-ventricle physiology. J Thorac Cardiovasc Surg. 2019;158:e73-4.

10. Emani SM. Lessons learned from Melody valve retrieved at transplantation. J Thorac Cardiovasc Surg. 2019;158:e74-5. 